\title{
CORRECTION
}

\section{Correction to: A new approach to $q$-linear Diophantine fuzzy emergency decision support system for COVID19}

\author{
Alaa O. Almagrabi ${ }^{1} \cdot$ Saleem Abdullah ${ }^{3} \cdot$ Maria Shams $^{3}$ (D) $\cdot$ Yasser D. Al-Otaibi ${ }^{2} \cdot$ Shahzaib Ashraf $^{3}$
}

(c) Springer-Verlag GmbH Germany, part of Springer Nature 2021

\section{Correction to: \\ Journal of Ambient Intelligence and Humanized Computing https://doi.org/10.1007/s12652-021-03130-y}

In the original article, the affiliation of first author has been incorrectly published.

The correct affiliation is as below:

Department of Information Systems, Faculty of Computing and Information Technology, King Abdulaziz University, Jeddah, 21589, Saudi Arabia.

The original article has been corrected.

The original article can be found online at https://doi.org/10.1007/ s12652-021-03130-y.

Maria Shams

mariaakhunzada@gmail.com

Alaa O. Almagrabi

aalmagrabi3@kau.edu.sa

Saleem Abdullah

saleemabdullah81@yahoo.com

Yasser D. Al-Otaibi

yalotaibi@kau.edu.sa

Shahzaib Ashraf

shahzaibashraf@awkum.edu.pk

1 Department of Information Systems, Faculty of Computing and Information Technology, King Abdulaziz University, Jeddah 21589, Saudi Arabia

2 Department of Information Systems, Faculty of Computing and Information Technology in Rabigh, King Abdulaziz University, Jeddah 21589, Saudi Arabia

3 Department of Mathematics, Abdul Wali Khan University Mardan, Mardan, Khyber Pakhtunkhwa, Pakistan
Publisher's Note Springer Nature remains neutral with regard to jurisdictional claims in published maps and institutional affiliations. 